\title{
Identifying Resilient and Non-Resilient Labour Conditions in Europe Using Qualitative Comparative Analysis
}

\author{
Sandra Martínez-Molina, \\ Polibienestar Research Institute (University of Valencia), \\ Paula Sabater Pavía, \\ Polibienestar Research Institute (University of Valencia),
}

Jorge Garcés Ferrer,

Prince of Asturias Distinguished Visiting Professor at Georgetown University,

Polibienestar Research Institute (University of Valencia),

\begin{abstract}
Based on the concept of labour market resilience, this paper is aimed to determine the combination of initial conditions behind resilient and non-resilient labour markets after the financial crisis in 2008 in Europe. We start from the assumption that some initial conditions in 2007 are crucial to achieve a specific labour result when a shock appears. In this sense, the effect of temporary employment in cyclical sectors, labour market flexibility, the level of education among the workforce, and the expenditure on Labour Market Policies (LMP) have been tested using crisp-set Qualitative Comparative Analysis (csQCA) in 25 European countries. Whilst our results do not explain labour market resilience in its entirety, we have found a model explaining $85 \%$ of the non-resilient cases. These findings suggest that the different levels of initial conditions may have prompted dissimilar labour adjustments with varying success rates in dealing with the job losses.
\end{abstract}

Keywords: resilience, labour market, economic crisis, crisis effects, Qualitative Comparative Analysis (QCA), European Union.

\section{Introduction}

Based on the concept of labour market resilience, the aim of this paper is to determine the combination of conditions that are behind both resilient and non-resilient labour markets after the onset of the financial crisis in 2008 in Europe.

The crisis had a clear impact not only on the economy but also on the labour markets, deteriorating the employment figures (Arpaia \& Curci, 2010; Brada \& Signorelli, 2012; Eichhorst, Escudero, Marx, \& Tobin, 2010a; Lallement, 2011; Marelli, Patuelli, \& Signorelli, 2012a; Marelli, Signorelli, \& Tyrowicz, 2012b; Tridico, 2013; Vaughan-Whitehead, 2011). However, such deterioration has been dissimilar as the different European labour markets have shown a range of strategies in dealing with the crisis to reduce its effects on the workforce (Ball, 2014; Bell \& Blanchflower, 2011; Eichhorst et al., 2010a; Guichard and Rusticelli, 2010; OECD, 2010; Verick, 2009).

Given this diversity, the term of resilience has emerged as an important concept explaining these differences. Although this concept has been widely applied to a large number of disciplines to generally describe the ability of a system to bounce back to a previously favourable state (Bahadur, Ibrahim, \& Tanner, 2010), the term has been recently linked to the labour market in order to explain its ability to deal with economic shocks (Bigos, Qaran, Fenger, Koster, Mascini, \& van deer Veen, 2013; Fenger, Koster, Struyven, \& van der Veen, 2014; Murias, Martínez-Roget, Novello, \& Estévez-Núñez, 2012; OECD, 
2012). In light of such an idea, the key question that arises is which causal configurations might reinforce labour market resilience and which ones weaken it.

Whilst there is a large body of research focused on those general factors that can affect the capacity of an economy or region to resist and recover after an economic shock, there are limited studies analysing those factors which enhance labour market resilience. Considering this gap, the purpose of this study is to identify the combination of initial conditions that are behind the resilient and non-resilient labour markets in the European countries during the crisis by using Qualitative Comparative Analysis (QCA). We start from the assumption that some initial labour conditions given before the crisis are crucial in explaining labour market results in the short term when a shock appears (Arpaia \& Curci, 2010; OECD, 2012).

\section{Theoretical Framework}

In this section, the main interpretations of the concept of resilience are reviewed, the main ways of conceptualisation and operationalisation of the labour resilience found in literature are pinpointed, and those potential factors affecting the performance of labour markets and resilience are discussed.

\section{Main approaches and interpretations of the resilience concept in the literature}

Etymologically, the term resilience comes from the Latin word resilire, which means to leap back or to rebound after a shock. During the last years, different disciplines have widely applied the concept of resilience, hampering its conceptualisation and operationalisation (Bahadur et al., 2010; Lisnyak, 2015; Martin, 2012; Martin \& Sunley, 2014; Simmie \& Martin, 2010). Be that as it may, engineering, ecological, and adaptive systems are the three perspectives commonly accepted in literature (Di Caro, 2014; Martin, 2012; Martin \& Sunley, 2014; Simmie \& Martin, 2010).

Under the engineering approach, resilience relies on the idea of equilibrium or bounce back (Martin \& Sunley, 2014). Within this approach, a shock displaces a system from its equilibrium state, and its resilience capacity refers to its ability to return to its pre-shock equilibrium (Folke et al., 2010; Martin \& Sunley, 2014; Pendall, Foster, \& Cowell, 2010).

From an ecological perspective, the concept of resilience emphasizes two points: the absorption capacity of a system and the idea of multiple equilibria. Thus, the ecological approach is primarily focused on the absorption capacity of a system without alterations in state, structure, function, and identity (Berkes \& Folke, 1998; Martin \& Sunley, 2014; Rose, 2009; Walker et al., 2006). However, if a shock exceeds that elasticity threshold, this disturbance will push the system into some other alternative equilibrium which might be different to the pre-equilibria, implying changes in its structure and function (Martin \& Sunley, 2014; Walker et al., 2006).

The third interpretation, the so called adaptive resilience, builds upon the idea of bounce forward (Martin \& Sunley, 2014). This perspective places particular emphasis on the adaptation capacity of a system and how well it adapts its structure and functions to deal with a crisis (Boschma, 2015; Christopherson, Michie, \& Tyle, 2010; Martin \& Sunley, 2014; Simmie \& Martin, 2010).

\section{Conceptual definitions of labour market resilience}

While it is true that the concept of economic regional resilience has been studied in more detail in the last years, the literature related to labour market resilience is still scarce, with some specific but disjointed studies. These dissimilarities not only rely on the aforementioned different approaches but also on the kind of resilient ability applied to the labour market. In such a way, labour market resilience has been defined by considering the effects of the crisis on the workforce (Diodato \& Weterings, 2015; OECD, 2012) whereas it has also been understood as the capacity not only to resist, withstand, or quickly recover but also to renew, adjust, or re-orientate (Fenger et al., 2014). In accordance with this later approach, some definitions have also added the capacity of a labour market to mitigate the impact on employment levels, specifically for vulnerable groups (Bigos et al., 2013). In this way, this view takes it a step further since they also involve the capacity of a labour market to mitigate their impact on the employment levels, specifically for vulnerable groups (Bigos et al., 2013).

Thus, the labour resilience is sometimes linked to the ability of a labour market to bounce back or resist, while other approaches stress the labour market absorption ability or adaptability as a core aspect in line with the ecological and the adaptive approach. 


\section{Operational definitions of labour market resilience}

Generally speaking, the concept of resilience related to employment shocks has been measured in different ways (Lisnyak, 2015). Despite this variety, at least two ways of measuring resilience are stood out in the literature: resilience gauged through single variables, and resilience as a complex construct made up of different dimensions and indicators.

Within the first perspective, some authors have gauged resilience to economic shocks either considering unemployment (Murias et al., 2012; Tsai, Wilson, \& Rahman, 2015) or employment figures as the dependent variable (Augustine, Wolman, Wial, \& McMillen, 2013; Di Caro, 2014; Fingleton, Garretsen, \& Martin, 2012; Hill et al., 2011; Lungová, 2013; Martin, 2012). However, the employment level seems to be a key factor as their recovery might be more critical and might be compatible with different dynamics of unemployment (Brada \& Signorelli, 2012; Lungová, 2013; Martin, 2012).

Finally, some authors have considered resilience in broad terms as a construct composed of several dimensions and indicators beyond economic or labour factors. The idea behind is that one single attribute cannot explain a phenomenon as complex as resilience (Arpaia \& Bates, 2015; Bates, Angeon, \& Ainouche, 2014; Briguglio, Cordina, Bugeja, \& Farrugia, 2006; Briguglio, Cordina, Farrugia, \& Vella, 2009; EDAW \& AECOM, 2009; Kahsai, Yu, Middleton, Schaeffer, \& Jackson, 2015). Although every index differs from each other, commonly, indexes measuring resilience involve economic, educational, governmental, social and environmental areas.

\section{Potential factors affecting the labour market performance and its resilience}

An important question arising when studying labour market resilience is which factors lead to a resilient and non-resilient result when a crisis appears and in which way they are combined to lead to a specific outcome. From the labour market resilience theoretical framework, Bigos et al. (2013) and Fenger et al. (2014) have underlined several institutional, structural-demographic, and socio-economic variables which might explain labour market resilience. Based on their contributions, the labour market performance is contingent upon the country's socio-economic factors such as the size of industry, regional disparities, and industrial structure.

Similarly, other studies have underlined these factors. For instance, the importance of the industry and the economic structure relies on the sensitivity of some economic sectors to shocks (Martin, 2012). In this regard, manufacturing, production, and construction have been considered as more cyclical sectors to the crisis (Barakat, Holler, Prettner, \& Schuste, 2010; Eichhorst et al., 2010a; Lungová, 2013; Marelli et al., 2012a; OECD, 2010). Subsequently, the higher the portion of these sectors in the economy, the higher damage to labour results and resilience (Martin, 2012; Murias et al., 2012).

Institutional factors might also be important for the labour market results and resilience by affecting the job creation and destruction, and explaining the unemployment figures (Arpaia \& Curci, 2010; Bigos et al., 2013; Duval, Eris, \& Furceri, 2011; Eichhorst et al., 2010a; Eichhorst, Feil, \& Marx, 2010b; OECD, 2012; Vaughan-Whitehead, 2011). Elements such as passive and active labour market policies, employment legislation, kind of contracts, and wages, among others, might be potential elements to take into account in the study of labour market resilience (Bigos et al., 2013; Brada \& Signorelli, 2012). Thus, when it comes to labour market results, labour market policies might be one of the key pillars.

Other findings suggest that the higher levels of flexibility, the higher levels of unemployment, diminishing its potential effect on labour market resilience (Marelli et al., 2012a; Tridico, 2013). Be that as it may, although the European countries are moving towards more flexible labour relations, there are large differences among them. Thereby, flexibility might not necessarily lead to bad labour market results as they depend on the different industrial relations systems where flexibility takes place (Miguélez \& Prieto, 2009).

Nevertheless, it seems that the different levels of the employment protection legislation together with labour market policies have allowed different labour adjustment during the crisis (Eichhorst et al., 2010b; OECD, 2012; Tridico, 2013). Adjustments based on internal flexibility, such as adjustments in working-time, have been considered as a key factor limiting the deterioration of employment figures (Arpaia \& Curci, 2010; Eichhorst et al., 2010b; Marelli et al., 2012a). Conversely, temporary workers have borne the brunt of employment losses across countries during the crisis (Arpaia \& Curci, 2010; Eichhorst et al., 2010a; Marelli et al., 2012a; OECD, 2010; 2012; Sánchez, 2009; Tridico, 2013; Vaughan- Whitehead, 2011). According to Tridico (2013), responses based on external flexibility, such as dismissals, have been more common 
in those countries which had a higher level of temporary employment before the crisis. In addition, temporality in cyclical sectors such as manufacturing or construction might increase the negative effects on labour markets by increasing their cyclical effects as these sectors have strongly been hit by the crisis (Barakat, et al., 2010; Eichhorst et al., 2010a; Marelli et al., 2012a; OCDE, 2010).

Additionally, human capital is an important factor according to the literature (Brada \& Signorelli, 2012; Christopherson et al., 2010; Diodato \& Weterings, 2015; Eichhorst et al., 2010a; Lungová, 2013). The strength of high educational levels among the workforce not only benefits its ability to increase the employment levels but also to protect against unemployment (Augustine et al., 2013; Barakat, et al., 2010; Di Caro, 2014; Murias et al., 2012; Svoboda \& Maštálka, 2013; Tsai et al., 2015). According to Arpaia and Curci (2010), human capital is especially important when the responses to the crises require a sectoral reallocation of the workforce from a traditional declining sector.

This review suggests that some initial labour conditions might affect labour market resilience and non-resilience when a crisis occurs. Thus, considering the aforementioned factors, this paper is focused on determining which combination of initial conditions of the labour markets in 2007 may lead to a resilient and non-resilient result after suffering a crisis. In this regard, initial conditions such as the level of education among the workforce, the level of expenditure on LMP, the proportion of temporary employment in construction and manufacturing, and the level of flexibility of the labour market in 2007 have been considered.

\section{Methods}

The sample includes all the European countries with available data regarding the variables of interest provided by official databases, involving 25 countries: Belgium, Bulgaria, Czech Republic, Denmark, Germany, Estonia, Ireland, Greece, Spain, France, Italy, Latvia, Luxembourg, Hungary, Netherlands, Austria, Poland, Portugal, Romania, Slovenia, Slovakia, Finland, Sweden, United Kingdom, and Norway.

The methodology used for the analysis was Qualitative Comparative Analysis (QCA), which focuses on testing alternative, theory-based, complex (conjunctive) causal recipes of antecedent conditions -including context influences- (Woodside and de Villiers, 2011). In particular, crisp-set QCA (csQCA) was the chosen modality, and the software used to perform the analysis was $\mathrm{R}$ software (R Core Team, 2015). Crisp-set QCA is based on the Boolean algebra, which includes two qualitative different states: true (or present), represented by 1 ; and false (or absent), represented by 0 (Ragin, 1987). Their main steps are the truth table performance and the Boolean minimisation (Thiem and Duşa, 2013) with the aim of identifying sufficient and necessary conditions (Schneider and Wageman, 2012). One condition (the term used in QCA when referring to a variable) is necessary for a specific outcome if the condition must be present for the outcome to occur (Ragin, 1987). In other words, the outcome will not occur in the absence of that condition. However, the condition may be present without leading to the outcome. On the other hand, one condition is sufficient for a specific outcome if such outcome occurs whenever the condition is present, although the outcome may come from other conditions. As the aim of this paper is to identify the combination of conditions leading to labour resilience -or not resilience-, and a necessary condition may be present without the outcome, only the analysis of sufficiency will be performed. In the analysis of sufficiency, the first step is to perform the truth table from the raw data, which is a table similar to a database showing all the possible logical combinations of the conditions included in the analysis. In the truth table, each row is a different configuration, denoting a qualitative different combination of conditions (Schneider and Wagemann, 2012). The analysis of sufficiency and the Boolean minimisation come out of the truth table. The Boolean minimisation is a procedure for determining necessity and sufficiency and for reducing explanations to its minimum expression. In accordance to Ragin (1987): "If two Boolean expressions differ only in one condition and nevertheless both reproduce the same outcome, then, the causal condition that distinguishes both expressions can be considered irrelevant and can be removed to create a new expression simpler than before". QCA provides three solutions: the complex solution, the parsimonious solution, and the intermediate one. The solution presented in this study is the parsimonious solution as it is the only one representing causal structures (Baumgartner, 2013).

Regarding the parameters of fit, the solution provides two measures named consistency and coverage. According to Ragin (2006), "set-theoretic consistency assesses the degree to which the cases sharing a given condition or combination or conditions [...] agree in displaying the outcome in question". In other words, the consistency indicates how many cases with a specific configuration show a positive outcome. On the other hand, set-theoretic coverage "assesses the degree to 
which a cause or causal combination accounts for instances of an outcome" (Ragin, 2006). This definition implies that the coverage indicates how many cases with a positive outcome show the configuration or configurations included in the solution, giving the proportion of cases explained by the solution.

On the basis of the different approaches of resilience aforementioned, the concept of labour resilience and non-resilience in this paper is built upon the engineering approach, understanding labour market resilience as the ability of a labour market to bounce back to its pre-crisis equilibrium in order to study resilience in the short term. Based on such approach, the outcome (labour resilience) has been defined in terms of employment figures following previous studies (Augustine et al., 2013; Di Caro, 2014; Fingleton et al., 2012; Hill et al., 2011; Lungová, 2013; Martin, 2012). According to other studies, the time framework has been defined from 2007 to 2010 so as to study how initial conditions in 2007 can affect labour market resilient in the short term (Bigos, Qaran, Fenger, Koster, \& van der Veen, 2014; Tsai et al., 2015). Bearing in mind this time framework, if the difference in the employment rate between 2007 and 2010 was positive or zero, and the employment levels did not drop in 2011 in relation to 2007, that country has been regarded as resilient and calibrated as 1 . On the other hand, if the difference was negative, it has been considered as not resilient due to the fact that the country was not able to overcome the impact of the economic crisis and it has been calibrated as 0 . In such a way, and following the engineering approach, we are able to measure the ability of a labour market to bounce back to its pre-crisis equilibrium.

As the main objective of this paper is to determine the combination of initial conditions that are behind resilient and nonresilient labour markets, every variable has been considered as present (1) if the initial value in 2007 was equal or higher than the median of the countries included in the study in that specific condition. Otherwise, they have been considered as not present and calibrated as 0 .

(Here Table 1)

\section{Results}

In this section, the main findings of the study are presented according to the following model:

Resilience $=\mathrm{f}$ (flexibility, labour market policies, educational level, cyclic temporary work)

Building upon the definition of labour resilience provided in the previous section, only five countries of the sample were resilient as they were able to maintain or even increase their employment rate between 2007 and 2010: Germany, Luxembourg, Austria, Poland, and Romania. The other European countries included in the study (Belgium, Bulgaria, Czech Republic, Denmark, Estonia, Ireland, Greece, Spain, France, Italy, Latvia, Hungary, Netherlands, Portugal, Slovenia, Slovakia, Finland, Sweden, United Kingdom, and Norway) were non-resilient in 2010.

Initially, the analysis of the sufficient conditions leading to a resilient outcome was performed but, since there are only five resilient countries and the cases included in the truth table (Table 2) are only three, the solution (Table 3 ) only explains $60 \%$ of the resilient cases. The symbol * represents the logical operator AND, thus the conditions connected by this symbol conform to a sufficient configuration leading to the outcome when the solution provides good values in the parameters of fit (consistency and coverage).

\section{(Here Table 2)}

As mentioned above, only Austria, Poland, Germany, Romania, and Luxembourg achieved a resilient outcome in 2010. The analysis of sufficiency for the resilient countries (Table 3 ) shows that there is a unique configuration leading to a resilient outcome, present in $60 \%$ of the resilient cases (Austria, Poland, and Germany). Specifically, the solution implies that those countries which had a higher level of education among the workforce than the median, and a higher expenditure on labour market policies together with a higher level of temporary employment in cyclical sectors in 2007, were resilient in 2010. As highlighted in the theoretical framework, the combination of human capital and labour market policies is especially important when the responses to the crises require a sectorial reallocation of the workforce (Arpaia \& Curci, 2010; Eichhorst et al., 2010a). In this sense, according to Eurostat data (2015), Germany was the country with the third highest employment loss in manufacturing, after the UK and Spain. In addition, Austria and Poland also registered a decrease in this indicator although it was not as significant as in Germany. In spite of this fact, the total level of employment in these countries increased from 2007 to 2010, suggesting a possible redistribution of the unemployed from this sector to others. 
Nevertheless, although the solution provided by the analysis of sufficiency has a consistency equal to 1 , which indicates that no non-resilient country had this configuration, there are only three resilient countries included in the solution and the coverage of 0.60 is not good enough to draw any firm conclusion about the causal configurations leading to labour resilience. Therefore, the conclusions reached through the analysis of sufficient conditions for resilience are not conclusive and must be taken with great caution.

(Here Table 3)

Regarding the non-resilient countries, the truth table includes seventeen cases (Table 4). As seen in table 5, there is only one solution including five prime implicants leading to a non-resilient outcome in our study. This solution has a consistency equal to 1 , meaning that every country showing one of the configurations included in the solution have been non-resilient. In other words, no resilient country shows any of these configurations. Moreover, the solution coverage is good as this solution explains $85 \%$ of the non-resilient cases.

\section{(Here Table 4)}

\section{(Here Table 5)}

The first configuration included in the solution involves the cases of Bulgaria, United Kingdom, and Greece, and implies that an initial expenditure on labour market policies (LMP) lower than the median together with a low temporary employment in cyclical sectors is sufficient to lead to a non-resilient labour market result. According to the literature review, a low level of temporary employment in cyclical sectors is deemed to be a potential resilient factor (Arpaia \& Curci, 2010; Barakat et al., 2010; Eichhorst et al., 2010a; 2010b; Lungová, 2013; OECD, 2010; 2012; Sánchez, 2009; Tridico, 2013; VaughanWhitehead, 2011). However, the results have shown that the countries with a low level of this condition are non-resilient if it is combined with a level of expenditure on active market policies below the median.

The second prime implicant leading to a non-resilient outcome includes an educational level higher than the median together with a low expenditure on active policies in 2007. This prime implicant has been present in Czech Republic, Estonia, Slovenia, Latvia, Hungary, and Slovakia. Although a high level of education has been regarded as a positive aspect in the literature due to its ability to increase the employment levels and to protect against unemployment (Augustine et al., 2013; Barakat, et al., 2010; Di Caro, 2014; Murias et al., 2012; Svoboda \& Maštálka, 2013; Tsai et al., 2015), the combination of this factor with a low expenditure on active policies has led to a non-resilient result. This finding suggests that, due to the lack of a high expenditure on active policies, some labour adjustments might not be possible when a crisis occurs. According to Arpaia and Curci (2010), the combination of a high level of both variables is important when the responses to the crises require external flexibility practices such as sectoral redistribution of the workforce from a traditional declining sector.

The third prime implicant includes an initial educational level lower than the median together with a high flexibility, present in Belgium, Denmark, Ireland, Netherlands, and Italy. This result could shed light on the effect of flexibility in combination with other factors. As noted in the previous section, the effect of flexibility in labour markets can be different depending on the context (Miguélez and Prieto, 2009). In this way, QCA is advantageous in finding different combinations leading to an outcome, which is known as equifinality. This fact implies that the effect of one condition might be different when it is combined with diverse conditions.

The fourth configuration combines a high initial educational level and a low temporary employment in cyclical sectors, involving Bulgaria, United Kingdom, Finland, and Sweden. Although both indicators are understood as potential conditions leading to a resilient result, these countries were non-resilient. The case of the United Kingdom is remarkable as it had the highest loss in manufacturing employment together with the second highest drop in the construction sector from the sample. Once again, the results suggest that these labour markets did not have enough tools to deal with the job losses when a crisis occurs despite presenting both conditions.

Finally, the last configuration leading to a non-resilient outcome includes an initial educational level lower than the median together with a high expenditure on labour policies and a high temporality in cyclical sectors. This configuration, covering only the case of Spain, suggests that a high level of expenditure on LMP is not enough to lead to a resilient labour market if there is a high proportion of temporary employment in cyclical sectors combined with a low level of education among the 
workforce. According to Eurostat (2015), Spain was the country with the highest employment losses in the construction sector and the second one in manufacturing losses, after the United Kingdom. Consequently, a low level of education among the workforce may hamper some labour adjustments based on the redistribution of unemployed people from these sectors to others, even when there is a high expenditure on LMP (Arpaia and Curci, 2010; Eichhorst et al., 2010a).

In light of the aforementioned results, the findings suggest that the variables analysed do not explain the resilience satisfactorily, but they explaine the non-resilient results. Therefore, the stated hypothesis cannot be verified as no resilient country presented it. However, a similar configuration has been found in Germany, which, unlike the initial assumption, had a level of temporary employment in cyclical sectors over the median.

As for non- resilient cases, although both a low level of temporality in cyclical sectors and a high level of education among the workforce are considered positive conditions in themselves to achieve resilient labour markets, the combination of each of them with a low expenditure on LMP in 2007 led to a non-resilient result in 2010, as shown in configurations one and two. In the same way, a high level of education in 2007 together with either a low expenditure on LMP or low temporary employment in cyclical sectors led to a non-resilient result as seen in configurations two and four. Finally, as for the temporary cyclical sectors, the same situation occurs when a low level of this condition, considered as a positive factor leading to a resilient result, is combined with either a low level of expenditure on LMP or a high educational level, resulting in a non-resilient labour market.

\section{Conclusions}

Building on the concept of resilience, the aim of this paper was to determine the combination of initial conditions that can lead to a resilient or non-resilient labour market result after the impact of the financial crisis in 2008. This article started from the statement that some initial labour conditions can matter for resilience and non-resilience labour market when a shock appears. Specifically, it was upheld that labour markets which had a high proportion of workforce with a high level of education, a high expenditure on labour market policies, and a low level of temporary employment in construction and manufacturing in 2007 were more likely to be resilient in 2010. In addition, as the potential effect of labour flexibility is not clear in the literature, this variable was included into the model so as to test its implication.

Thus, the model: Resilience $=\mathrm{f}$ (flexibility, labour market policies, educational level, cyclic temporary work) has been tested by using the csQCA methodology in order to find causal configurations leading to a resilient and non-resilient result.

Based on the engineering approach, labour market resilience has been understood as the ability to bounce back to the precrisis equilibrium. In this regard, resilience has been operationalised considering the employment levels from 2007 to 2010. Resilient countries were those in which employment levels in 2010 were, at least, the same as 2007 and did not experienced a drop in 2011 in relation to 2007, while non-resilient countries were those which could not bounce back to their pre-shock levels of employment in 2010.

The results have revealed that there were more non-resilient countries than resilient ones in the European labour markets since only Germany, Luxembourg, Austria, Poland, and Romania were resilient according to the definition provided. Besides, the findings show that the variables analysed do not explain the resilience in a satisfactory way, since a combination of factors covering $60 \%$ of resilient countries has been found. However, the results have shown the configurations that can lead to non-resilient labour markets explaining $85 \%$ of non-resilient cases. The analysis of sufficiency for non-resilience has provided one solution with five prime implicants suggesting that different combinations of initial conditions may have prompted dissimilar labour adjustment dealing with the job losses.

However, as mentioned above, the study has had some limitations explaining the phenomenon of resilience. These limitations are mainly due to the scarcity of resilient cases and the coverage of the model. In this sense, the number of resilient and non-resilient countries in 2010 was very unbalanced. In addition, some resilient countries, such as Malta, Switzerland, and Macedonia, were eliminated from the sample due to a lack of available data of the variables included in the model. Therefore, both these facts might have affected the relevance of the results regarding resilient labour markets. Given such circumstances, it has been considered that these limitations could be overcome by studying resilience in a long-term perspective, amplifying the temporal dimension. By implementing this change, the sample of resilient countries could be larger as more countries might have recovered. However, the idea that the impact of the initial labour conditions 
should be studied in the short-term after a shock has been supported. Otherwise, the effect of the responses from the governments may diminish the impact of the initial labour conditions due to fact that effect of different policies implemented during the crisis would appear in the results.

Another issue is that, since resilience has been considered as the ability of a labour market to bounce back to its pre-crisis level of employment, if the pre-crisis level of employment was high or not in a country in itself has been left out. Therefore, under this model, some countries have not been considered as resilient as they did not meet the resilience condition in spite of having high initial levels of employment (e.g., Norway). Such a fact has been understood as a limitation of the study since promoting and maintaining high levels of employment is a key issue in the European labour policies which may be considered as an aspect of resilience. Nevertheless, the objective of this article was to study labour resilience from the engineering perspective which does not take into account this aspect.

Besides the limitation of the operationalisation of resilience, the calibration was based on the median of the sample countries which facilitated the division into two parts of the distribution data. Given the difficulty of establishing a threshold for every variable when there is not any theoretical cut-off point related to such issue, the median was chosen as this threshold.

Be that as it may, the present research has contributed to broadening knowledge of the conceptual framework of labour market resilience by identifying different configurations of conditions leading to non-resilient labour markets during the crisis. According to our knowledge of the subject, this work is a pioneering study as it represents the first research of labour market resilience by using the Qualitative Comparative Analysis methodology (QCA) to date. Therefore, this work provides a first approximation in the study of labour market resilience by using the aforementioned methodology and this study could serve as a model for future works.

As the results obtained have implied that some variables might be relevant allowing some kinds of labour adjustments, future research should focus on the sort of adjustments and responses carried out by resilient and non-resilient countries. This approach will allow us to study labour market resilience in the long-term, amplifying the time framework and increasing the number or resilient countries so as to overcome the limitations of this work.

\section{References}

[1] Angeon, V., \& Bates, S. (2015). Reviewing Composite Vulnerability and Resilience Indexes: A Sustainable Approach and Application, World Development, 72, 140-162.

[2] Arpaia, A., \& Curci, N. (2010). EU labour market behaviour during the Great Recession Economic Papers 405. http://ec.europa.eu/economy_finance/publications/economic_paper/2010/pdf/ecp405_en.pdf. Accessed 26 February $\underline{2016 .}$

[3] Augustine, N., Wolman, H., Wial, H., \& McMillen, M. (2013). Regional Economic Capacity, Economic Shocks, and Economic Resilience, BRR working paper 2013, Institute of Urban and Regional Development, Berkeley. http://brr.berkeley.edu/wp-content/uploads/2013/05/Augustine-resilience-capacity2.pdf. Accessed 26 February 2016.

[4] Bahadur, A.V., Ibrahim, M., \& Tanner, T. (2010). The resilience renaissance? Unpacking of resilience for tackling climate change and disasters. CSR Discussion Paper No.1, Strengthening Climate Resilience programme, Brighton: IDS. http://www. fsnnetwork.org/sites/default/files/ids_resilience-renaissance.pdf. Accessed 26 February 2016.

[5] Ball, L.M. (2014). Long-term damage from the great recession in OECD countries. NBER Working Paper No. 20185. http://www.nber.org/papers/w20185.pdf. Accessed 26 February 2016.

[6] Barakat, B., Holler, J., Prettner, K. \& Schuste, J. (2010). The impact of the crisis on labour and education in Europe, Vienna Institute of Demography Working Paper. http://www.oeaw.ac.at/vid/download/WP2010 06.pdf. Accessed 26 February 2016.

[7] Bates. S.. Anceon. V.. \& Ainouche. A. (2014). The nentacon of vulnerabilitv and resilience: A methodological proposal in development economics by using graph theory. Economic Modelling, 42, 445-453.

[8] Baumgartner, M. (2013). Parsimony and Causality. Quality and Quantity, 49, 839-856.

[9] Bell, D. N. F., \& Blanchflower, D. G. (2011). Youth unemployment in Europe and the United States, Discussion paper series, Forschungsinstitut zur Zukuntt der Arbeit, No. 5673. http://nbn-resolving.de/urn:nbn:de:101:1-201105173099. Accessed 26 February 2016. 
[10] Berkes, F., \& Folke, C. (1998). Linking Social and Ecological Systems: Management Practices and Social Mechanisms for Building Resilience. New York: Cambridge University Press.

[11] Bernal-Verdugo, L.E., Furceri, D., \& Guillaume, D. (2012). Labour Market Flexibility and Unemployment: New Empirical Evidence of Static and Dynamic Effects, Comparative Economic Studies, 54, 251-73. doi:10.1057/ces.2012.3

[12] Bigos, M., Qaran, W., Fenger, M., Koster, F., Mascini, P., \& van deer Veen, R. (2013). Review essay on labour market resilience [D1.1]. http://www.inspires-

research.eu/userfiles/D1_1\%20Review\%20Essay\%20on\%20Labour\%20Market\%20Resilience.pdf. Accessed 26 February 2016.

[13] Bigos, M., Qaran, W., Fenger, M., Koster, F., \& van der Veen, R. (2014). Benchmark Report on Labour market resilience. http://www.inspires-

research.eu/userfiles/D1_3\%20Benchmark\%20Report\%20on\%20Labour\%20market\%20resilience.pdf. Accessed 26 February 2016.

[14] Boschma, R. (2015). Towards an Evolutionary Perspective on Regional Resilience, Regional Studies, 49, $733-751$. doi: $10.1080 / 00343404.2014 .959481$

[15] Brada, J., \& Signorelli, M. (2012). Comparing Labour Market Performance: Some Stylized Facts and Key Findings, Comparative Economic Studies, 54, 231-250.

[16] Briguglio, L., Cordina, G., Bugeja, S., \& Farrugia, N. (2006). Conceptualizing and Measuring Economic Resilience. Working paper, Economics Department, University of Malta. https://www.um.edu.mt/_data/assets/pdf_file/0013/44122/resilience_index.pdf. Accessed 26 February 2016.

[17] Briguglio, L., Cordina, G., Farrugia, N., \& Vella, S. (2009). Economic vulnerability and resilience: Concepts and measurements, Oxford Development Studies, 37, 229-247.

[18] Christopherson, S., Michie, J., \& Tyle, P. (2010). Regional resilience: theoretical and empirical perspectives, Cambridge Journal of Regions Economy and Society, 3, 3-10. doi:10.1093/cjres/rsq004

[19] Di Caro, P. (2014). Recessions, recoveries and regional resilience: evidence on Italy, Cambridge Journal of Regions, Economy and Society, 8, 273-291. doi: 10.1093/cjres/rsu029

[20] Diodato, D., \& Weterings, A.B.R. (2015). The resilience of regional labour markets to economic shocks: exploring the role of interactions among firms and workers, Journal of Economic Geography, 15: 723-742. doi:10.1093/jeg/lbu030

[21] Duval, R., Eris, M., \& Furceri, D. (2011). The Effects of Downturns on Labour Force Participation: Evidence and Causes, OECD Economics Department Working Papers, No. 875, OECD Publishing. http://www.oecdilibrary.org/economics/the-effects-of-downturns-on-labour-force-participation 5kg9q0nmbws8-en?crawler=true. Accessed 26 February 2016.

[22] EDAW \& AECOM (2009). Index of Economic Resilience, Sheffield City Region Report, Reference 208632. http://sheffieldcityregion.org.uk/wpcontent/themes/lepress/Downloads/Index\%20of\%20Economic\%20Resilience\%20Report.pdf. Accessed 26 February 2016.

[23] Eichhorst, W., Escudero, V., Marx, P., \& Tobin, S. (2010a). The impact of the crisis on employment and the role of labour market institutions, IZA Discussion Paper No. 5320, Institute for the Study of Labor (IZA), Bonn. http://ftp.iza.org/dp5320.pdf. Accessed 26 February 2016.

[24] Eichhorst, W., Feil, M.T., \& Marx, P. (2010b). What crisis? Patterns of adaptation in European labour markets, IZA Discussion Paper No. 5045, Institute for the Study of Labor (IZA), Bonn. http://ftp.iza.org/dp5045.pdf. Accessed 26 February 2016.

[25] Eurostat Unemployment Statistics (2015) Labour Force Survey (LFS). http://ec.europa.eu/eurostat/web/labourmarket/statistics-illustrated. Accessed 26 February 2016.

[26] Fenger, M., Koster, F., Struyven, L., \& van der Veen, R. (2014). Smart Policies or Sheer Luck? Labour Market Resilience in the Low Countries, Social policy and administration, 48, 492-513.

[27] Fingleton, B., Garretsen, H., \& Martin, R. (2012). Recessionary shocks and regional employment: evidence on the resilience of U.K. regions, Journal of regional science, 52, 109-133.

[28] Folke, C., Carpenter, S. R., Walker, B., Scheffer, M., Chapin, T., \& Rockström, J. (2010). Resilience thinking: integrating resilience, adaptability and transformability, Ecology and Society, 15. 
[29] Guichard, S., \& Rusticelli, E. (2010). Assessing the Impact of the Financial Crisis on Structural Unemployment in OECD Countries. OECD Economics Department Working Papers, No. 767, OECD Publishing. http://www.oecdilibrary.org/economics/assessing-the-impact-of-the-financial-crisis-on-structural-unemployment-in-oecdcountries_5kmftp8khfjg-en?crawler=true. Accessed 26 February 2016.

[30] Hill, E., Clair, T., Wial, H., Wolman, H., Atkins, P., Blumenthal, P., Ficenec, S., \& Friedhoff, A. (2011). Economic Shocks and Regional Economic Resilience, working paper 2011-03, Institute of Urban and Regional Development, Berkeley. http://brr.berkeley.edu/brr_workingpapers/2011-03-hill_et_alconference economic shocks regional economic resilience.pdf. Accessed 26 February 2016.

[31] Kahsai, M.S., Yu, J., Middleton, M., Schaeffer, P.V., \& Jackson, R.W. (2015). Regional Research Institute West Virginia University. An Application to West Virginia, Working Paper Number 2015-03. http://rri.wvu.edu/wpcontent/uploads/2012/11/WP CERI.pdf. Accessed 26 February 2016.

[32] Lallement, M. (2011). Europe and the economic crisis: forms of labour market adjustment and varieties of capitalism, Work, employment and society, 25, 627-641.

[33] Lisnyak, S. (2015). Literature review regarding the concept of resilience and its assessment in the context of the economic dimension, CES Working Papers, issue: 2A, 511-518.

[34] Lungová, M. (2013). The resilience of regions to economic shocks https://dspace.tul.cz/bitstream/handle/15240/6932/38\%20363.pdf?sequence=1. Accessed 26 February 2016.

[35] Marelli, E., Patuelli, R., \& Signorelli, M. (2012a). Regional unemployment in the EU before and after the global crisis, Post-Communist Economies, 24, 155-175.

[36] Marelli, E., Signorelli, M., \& Tyrowicz, J. (2012b). Crises and joint employment-productivity dynamics: A comparative perspective for European countries, Comparative Economic Studies, 54(2), 361-394.

[37] Martin, R. (2012). Regional Economic Resilience, Hysteresis and Recessionary Shocks, Journal of Economic Geography, 12, 1-32. doi: 10.1093/jeg/lbr019

[38] Martin, R., \& Sunley, P. (2014). On the Notion of Regional Economic Resilience: Conceptualisation and Explanation Journal of Economic Geography, 15,1-42. doi: 10.1093/jeg/lbu015

[39] Miguélez, F. \& Prieto, C. (2009). Trasformaciones del empleo, flexibilidad y relaciones laborales en Europa, Política y Sociedad, 46, 275-287.

[40] Murias, P., Martínez-Roget, F., Novello, S., \& Estévez-Núñez, J.C. (2012). Resiliencia y mercados de trabajo locales: municipios españoles frente a la crisis, International Conference on Regional Science the challange of regional development in a world of changing hegemonies: knowledge, competitiveness and austerity, XXXVIII Reunión de Estudios Regionales- AECR. http://www.aecr.org/web/congresos/2012/Bilbao2012/htdocs/pdf/p380.pdf. Accessed 26 February 2016.

[41] OECD (2010). OECD Employment Outlook 2010, Paris, OECD Publishing. http://www.oecd.org/employment/emp/48806664.pdf. Accessed 26 February 2016.

[42] OECD (2012). OECD Employment Outlook 2012, Paris, OECD Publishing http://www.oecdilibrary.org/docserver/download/8112011e.pdf?expires=1456418624\&id=id\&accname=0cid194660b \&checksum=D9FAF4A3A7166CB65BCFEF312093F13F. Accessed 26 February 2016.

[43] Pendall, R., Foster, K., \& Cowell, M. (2010). Resilience and regions: building understanding of the metaphor, Cambridge Journal of Regions, Economy and Society, 3, 71-84. doi:10.1093/cjres/rsp028

[44] R Core Team (2015) R: A language and environment for statistical computing, R Foundation for Statistical Computing, Vienna, Austria. http://www.R-project.orgl. Accessed 26 February 2016.

[45] Ragin, C. (1987). The Comparative Method: Moving Beyond Qualitative and Quantitative Strategies. Berkeley: University of California Press.

[46] Ragin, C. (2006). Set relations in social research: Evaluating their consistency and coverage, Political Analysis, 14, $291-310$

[47] Rose, A. (2009). Economic Resilience to Disasters, CARRI Research Report 8.http://www.resilientus.org/wpcontent/uploads/2013/03/Research_Report_8_Rose_1258138606.pdf. Accessed 26 February 2016.

[48] Sánchez, A. (2009). Crisis y empleo: del mercado de trabajo al modelo económico. Revista Trabajo Universidad de Huelva, 22, 17-46. 
[49] Schneider, C., \& Wagemann, C. (2012). Set-Theoretic Methods for the Social Sciences: A Guide to Qualitative Comparative Analysis (QCA). Cambridge: Cambridge University Press.

[50] Simmie, J., \& Martin, R. (2010). The economic resilience of regions: towards an evolutionary approach, Cambridge Journal of Regions, Economy and Society, 3, 27-43. doi:10.1093/cjres/rsp029

[51] Svoboda, O., \& Maštálka, M. (2013). The resilience of Czech regions to economic crisis, XVI. mezinárodní kolokvium o regionálních vědách. Retrieved from: https://is.muni.cz/do/econ/soubory/katedry/kres/4884317/41725568/62_2013.pdf. Accessed 26 February 2016.

[52] Thiem, A., \& Duşa, A. (2013). Boolean Minimization in Social Science Research: A Review of Current Software for Qualitative Comparative Analysis (QCA), Social Science Computer Review, 31,505-21.

[53] Tridico, P. (2013). The impact of the economic crisis on EU labour markets: A comparative perspective, International Labour Review, 152, 175-190.

[54] Tsai, C., Wilson, P.N., \& Rahman, T. (2015). Economic Resilience and Vulnerability in the Rural West, University of Arizona, Department of Agricultural and Resource Economics, Working Papers. http://purl.umn.edu/202969. Accessed 26 February 2016.

[55] Vaughan-Whitehead, D. (2011). The effects of the crisis on work inequalities in Europe. Research Conference on Key Lessons from the Crisis and Way Forward. http://www.ilo.org/wcmsp5/groups/public/---dgreports/--inst/documents/genericdocument/wcms 192381.pdf. Accessed 26 February 2016.

[56] Verick, S. (2009). Who is Hit Hardest During a Financial Crisis? The Vulnerability of Young Men and Women to Unemployment in and Economic Downturn, Institute for the Study of Labor (IZA) Discussion Paper No. 4359. http://ftp.iza.org/dp4359.pdf. Accessed 26 February 2016.

[57] Walker, B., Gunderson, L., Kinzig, A., Folke, C., Carpenter, S., \& Schultz, L. (2006). A handful of heuristics and some propositions for understanding resilience in social-ecological systems, Ecology and Society, 11, 13.

[58] Woodside, A., \& de Villiers, R. (2011). Improving Research on Thinking and Deciding by Executives, 2011 4th international conference of education, research and innovation (iceri), p. 71.

[59] Acknowledgement

[60] S. Martínez-Molina is supported by a pre-doctoral FPU fellowship of the Spanish Ministry of Education (FPU13/05424). Thanks to Estrella Durá for her constructive comments, and to Polibienestar Research Institute (University of Valencia) and the Spanish Ministry of Education for their support.

\section{Conflict of Interest}

The authors declare that they have no conflict of interest.

\section{Tables}

Table 5: Description of the conditions

\begin{tabular}{|c|c|c|}
\hline & Description & Indicator \\
\hline $\begin{array}{l}\text { RES } \\
\text { Labour resilience }\end{array}$ & $\begin{array}{l}\text { Difference in the employment rate between } 2007 \text { and } \\
2010 .\end{array}$ & $\begin{array}{l}\text { Eurostat-Labour Force Survey- } \\
\text { LFS (Ifsa_ergan) }\end{array}$ \\
\hline & $\begin{array}{l}\text { Quantitative measure that considers various aspects of the } \\
\text { legal and regulatory framework of a country's labour }\end{array}$ & \\
\hline $\begin{array}{l}\text { FLEX } \\
\text { Flexibility }\end{array}$ & $\begin{array}{l}\text { market, including regulations concerning minimum wages, } \\
\text { laws inhibiting layoffs, severance requirements, and } \\
\text { measurable regulatory restraints on hiring and hours } \\
\text { worked. }\end{array}$ & $\begin{array}{l}\text { CESifo Group } \\
\text { (Labour Freedom-Index of } \\
\text { Economic Freedom) }\end{array}$ \\
\hline $\begin{array}{l}\text { EDU } \\
\text { Educational level }\end{array}$ & $\begin{array}{l}\text { Population with upper secondary or tertiary education } \\
\text { attainment. ISCED } 11 \text { Upper secondary, post-secondary } \\
\text { non-tertiary and tertiary education (levels 3-8). People from } \\
15 \text { to } 64 \text { years old. }\end{array}$ & $\begin{array}{l}\text { Eurostat-Education and } \\
\text { training (edat_Ifse_08) }\end{array}$ \\
\hline LMP & Data on expenditure cover the direct costs of total LMP & Eurostat-Labour Force Survey- \\
\hline
\end{tabular}


Labour Market

Policies

TEMCYC

Cyclic temporary work intervention (categories 2-7) as percentage of gross domestic product (GDP) including the following actions: training, employment incentives, supported employment and rehabilitation, direct job creation and start-up incentives.

The proportion of workers with temporary employment in manufacturing and construction workers in total temporary employment.
LFS

(Imp_expsumm)

Eurostat-Labour Force Survey-

LFS

(Ifsa_etgana)

Source: Own elaboration

Table 6: The truth table for the resilient cases

\begin{tabular}{|c|c|c|c|c|c|c|c|}
\hline EDU07 & FLEX07 & LMPLMP07 & TEMCYC07 & OUT & $\mathrm{n}$ & incl & cases \\
\hline 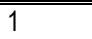 & 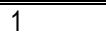 & 1 & 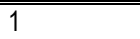 & 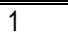 & 2 & 1,00 & "Austria,Poland \\
\hline 1 & 0 & 1 & 1 & 1 & 1 & 1,00 & Germany \\
\hline 0 & 0 & 0 & 1 & 0 & 2 & 0,50 & Portugal,Romania \\
\hline 0 & 0 & 1 & 0 & 0 & 3 & 0,33 & France,Luxembourg,Norway \\
\hline 0 & 1 & 1 & 0 & 0 & 4 & 0,00 & Belgium,Denmark,Ireland,Netherlands \\
\hline 1 & 0 & 0 & 1 & 0 & 3 & 0,00 & Czech Republic,Estonia,Slovenia \\
\hline 1 & 1 & 0 & 1 & 0 & 3 & 0,00 & Latvia,Hungary,Slovakia \\
\hline 1 & 1 & 0 & 0 & 0 & 2 & 0,00 & Bulgaria,United Kingdom \\
\hline 0 & 0 & 0 & 0 & 0 & 1 & 0,00 & Greece \\
\hline 0 & 0 & 1 & 1 & 0 & 1 & 0,00 & Spain \\
\hline 0 & 1 & 0 & 1 & 0 & 1 & 0,00 & Italy \\
\hline 1 & 0 & 1 & 0 & 0 & 1 & 0,00 & Finland \\
\hline 1 & 1 & 1 & 0 & 0 & 1 & 0,00 & Sweden \\
\hline
\end{tabular}

Table 7: Analysis of sufficient conditions for the labour resilience: parsimonious solution

\begin{tabular}{lccc}
\hline \hline Causal configuration & Consistency & Raw coverage & Unique coverage \\
\hline \hline & 1.00 & 0.60 & - \\
EDU07 ${ }^{*}$ LMP07 ${ }^{*}$ TEMCYC07 & & & \\
Solution consistency: 1.00 & & \\
Solution coverage: 0.60 & & \\
\hline \hline
\end{tabular}


Table 8: The truth table for the not resilient cases

\begin{tabular}{||llll|l|l|l|l||}
\hline \hline EDU07 & FLEX07 & LMP07 & TEMCYC07 & OUT & $\mathrm{n}$ & incl & cases \\
\hline \hline 0 & 1 & 1 & 0 & 1 & 4 & 1,00 & Belgium,Denmark,Ireland,Netherlands \\
1 & 0 & 0 & 1 & 1 & 3 & 1,00 & Czech Republic,Estonia,Slovenia \\
1 & 1 & 0 & 1 & 1 & 3 & 1,00 & Latvia,Hungary,Slovakia \\
1 & 1 & 0 & 0 & 1 & 2 & 1,00 & Bulgaria,United Kingdom \\
0 & 0 & 0 & 0 & 1 & 1 & 1,00 & Greece \\
0 & 0 & 1 & 1 & 1 & 1 & 1,00 & Spain \\
0 & 1 & 0 & 1 & 1 & 1 & 1,00 & Italy \\
1 & 0 & 1 & 0 & 1 & 1 & 1,00 & Finland \\
1 & 1 & 1 & 0 & 1 & 1 & 1,00 & Sweden \\
0 & 0 & 1 & 0 & 0 & 3 & 0,67 & France,Luxembourg,Norway \\
0 & 0 & 0 & 1 & 0 & 2 & 0,50 & Portugal,Romania \\
1 & 1 & 1 & 1 & 0 & 2 & 0,00 & Austria,Poland \\
1 & 0 & 1 & 1 & 0 & 1 & 0,00 & Germany \\
\hline
\end{tabular}

Table 9: Analysis of sufficient conditions for the absence of resilience: parsimonious solution

\begin{tabular}{lccc}
\hline \hline Causal configuration & Consistency & Raw coverage & Unique coverage \\
\hline \hline & & & \\
$\sim$ LMP07 * $\sim$ TEMCYC07 & 1.00 & 0.15 & 0.05 \\
EDU07 * $\sim$ LMP07 & 1.00 & 0.40 & 0.30 \\
$\sim$ EDU07 * FLEX07 & 1.00 & 0.25 & 0.25 \\
EDU07 * $\sim$ TEMCYC07 & 1.00 & 0.20 & 0.10 \\
$\sim$ EDU07 * LMP07 * TEMCYC07 & 1.00 & 0.05 & 0.05 \\
Solution consistency: 1.00 & & & \\
Solution coverage: 0.85 & & & \\
\hline \hline
\end{tabular}

